\title{
Design of driving lever air suction type seed metering device
}

\author{
Xiao Wang ${ }^{1, a}$, Xiao-rong LÜ ${ }^{1, b^{*}}$ Lin He ${ }^{1, c}$,Teng-fei Wu ${ }^{1, d}$ \\ 1 Sichuan Agricultural Uniersity, 46 xinkang road, Ya'an ,Sichuan, China

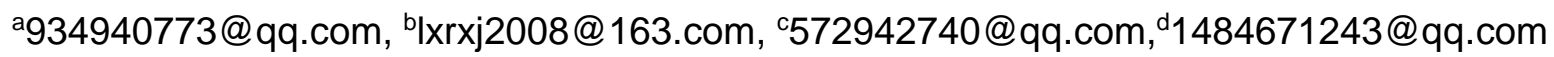

Keywords: Precision seeding, air suction type, seed metering device.

Abstract. In order to realize the precision seeding of big seeds such as peanut, in this paper we designed a seeding machine which is characterized in that it is provided with an adjustable intake pipe,The upper end of which is connected with the original air inlet pipe of the seeding machine, the lower end is communicated with the lower chamber of the seeding machine's air chamber, and set a through holes on it for install the driving lever. On the side wall of the planter roller we setting adjustment blocks which could extrude the driving lever to make it rotation control the opening and closing of the trachea. The structure can realize the replacement of the adjustment block rapidly during the seeding process, and through the plectrum to control the opening and closing of the intake pipe, thus, the regulation of the number and the spacing of the seeds in the seeding process can be realized.

\section{Introduction}

The seeding principle of the sowing device can be divided into mechanical and pneumatic two categories, because the pneumatic device on the seed size is not strictly, do not need to select grading, less injury, and easy to achieve a single grain on demand, planter's work speed to improve the potential of large, has been widely studied and applied. During the planting process for different or the same crop due to the different planting patterns, the number of each hole and the size of the hole will have different requirements, The distance between the existing air suction sowing machine and the adjustment of the number of seeds per planting generally done by replacing the sucker suction tray with a different number of suction holes and Duckbill assembly, because the seed suction plate installed inside of the Bunch wheel, adjust the hole spacing needs to remove the parts to complete the replacement of the seed suction plate, so disassembly is very troublesome, time-consuming and laborious, greatly affected the use of the effect of the machine in addition ${ }^{[1,2]}$. In order to improve the adaptability of the sowing machinery and the flexibility of operation, it is necessary to design the sowing machinery to carry out the effective adjustment of the number of seeds and the hill spacing between different planting requirements in the operation.

\section{The overall structure design and working principle of driving lever air suction type seed metering device.}

Overall Structure Design. Overall Structure Design of the driving lever air suction type seed metering device sampler studied in this paper is shown in the following figure. Referring to Figures 1 , The seed metering device is mainly composed of upper chamber, lower chamber and air pressure regulating device, Wherein the upper chamber and the lower chamber of the seed metering device are capable of forming a negative pressure under the action of the intake and exhaust of the air pressure regulating device to achieve the purpose of the seeding by cooperating with the seed weight.

Air pressure regulating device shown in Figure 2, It is mainly composed of adjustable intake pipe, driving lever mechanism and adjustment block, The adjustment block could control the movement of the driving lever mechanism so that which could be adjusted the adjustable intake pipe to control the air pressure in the upper chamber and the lower chamber to complete the planting operation. 


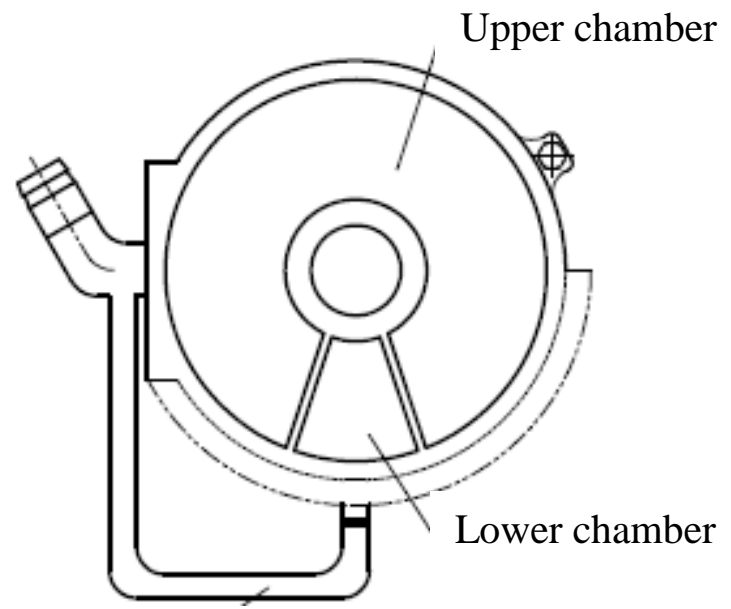

Fig.1

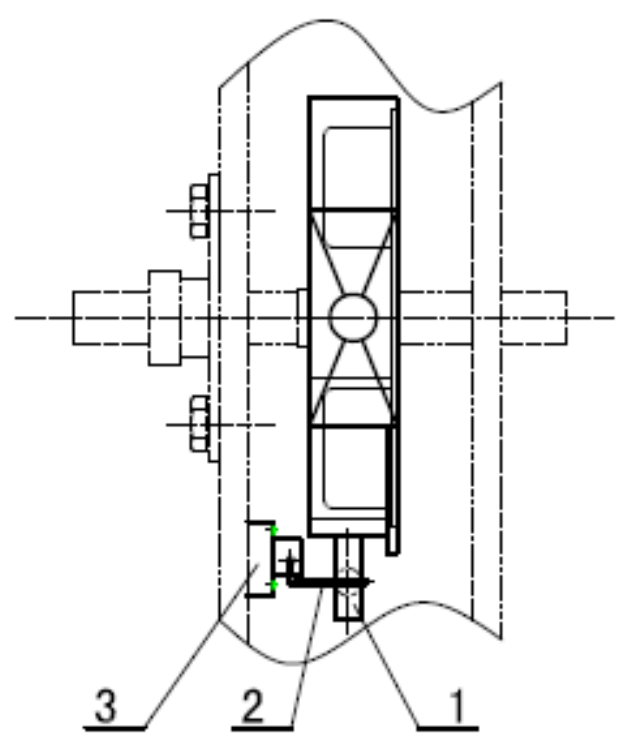

Fig.2

1. adjustable intake pipe 2. driving lever mechanism 3 . adjustment block

working principle.install the corresponding number and shape of adjustment block 3 on the drum side wall of the planter according to the planting pattern and the seeding number (When the speed of the Roller and the rotational speed of the Sucking plate are not changed, the adjustment block 3 mounted on the same circumference of the Roller side wall is less and the spacing of the seeding is larger. When the adjustment block 3 is pushed by 2 to cause the plectrum 22 to control the closing and opening of the adjustable intake pipe 1, the longer the closing time is, the longer the time to cut off the gas source, the more the number of particles per hole) So as to realize the hill spacing and the adjustment of the number of grains per hill.

The main structure design and working principle of driving lever air suction type seed metering device.

Design of the driving lever mechanism. In this design the driving lever mechanism play the major regulatory role for the structure, as shown in Figure 3, driving lever mechanism 2 is made up of driving lever 21, plectrum 22 Torsional spring 23 and Pressure block 24. driving lever 21 and plectrum 22 are fixed, Torsional spring 23 set on driving lever 21 one end of which is fixedly 
connected to the adjustable inlet pipe 1 and the other end of it is fixedly connected to the Pressure block 24.the Pressure block 24 is fixed at the end of driving lever 21.

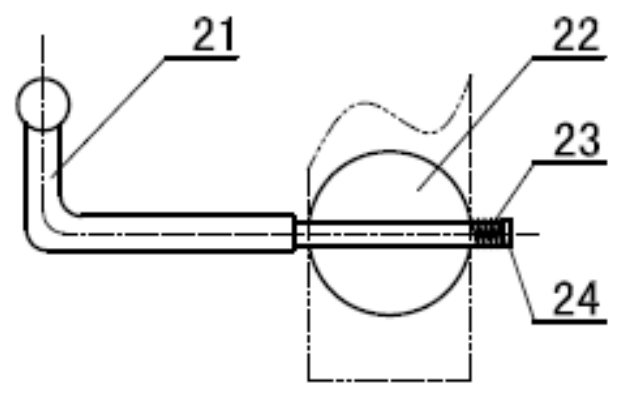

Fig. 3 driving lever mechanism

21. driving lever 22. plectrum 23. Torsional spring 24. Pressure block

Working principle.As shown in Figure 2 with the operation of the planter, the machine pulls the hill-drop wheel to rotate, through the transmission to shaft drives the seed suction tray to rotate relative to the seed chamber and the air chamber. At the same time, the intake pipe and the adjustable intake pipe 1 are all ventilated, In this way, the air chamber has negative pressure action in the upper and lower chambers, and the seed suction tray fully absorbed the seed in the seed chamber and carried the seed out of the seed chamber, When the seed suction tray is transferred to the lower portion of the chamber, Since The driving lever 21 rotates under the action of the adjustment block 3 on the rotating roller side plate which drives plectrum 22 rotates and closes the adjustable intake pipe 1, i.e., cuts off the lower chamber air supply. At this time the lower chamber is non-vacuum area, when the suction plate rotates to the lower chamber non-vacuum area due to suction negative pressure disappeared, the seeds rely on their own weight to fall, to achieve the sowing process When the adjustment block 3 leaves the driving lever 21 , the plectrum 22 is reset by the action of the torsional spring, and the lower chamber of the air chamber is restored to negative pressure. When the suction tray passes through the area, the seed is allowed to pass through the negative pressure.

Design of the adjustment block. In this design, the adjustment block is a cam, as shown in Figure 4 , the contour of the cam can effectively control the rotation time of the lever in the lever mechanism ${ }^{[3]}$, thus controlling the opening and closing time of the adjustable air pipe to control the number of seeds in each hole, At the same time, according to the number of the adjusting block on the seed tray and the distance between the adjacent two regulating blocks, the sowing time and the hill spacing can be controlled.

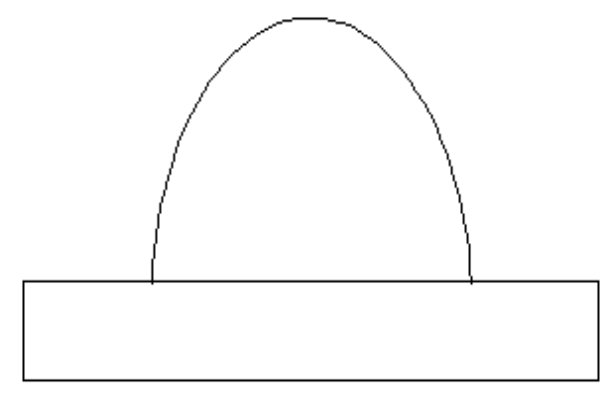

Fig.4 adjustment block

\section{The characteristics of driving lever air suction type seed metering.}

The design of the characteristics of the device can be based on planting patterns and planting the number of grain requirements, by quickly changing the shape of the adjustment block or increase or decrease the number of adjustment block to change the rotation position of the paddle of the dwell 
time and rotation frequency to control the opening and closing time of the adjustable intake trachea. Thus effectively realizing the change of the number of seeds and the hill spacing in each planting during the planting process.

\section{Conclusions}

1. The overall structure of the design simple and innovative, easy to operate, save time and effort,It is suitable for the fine seeding of peanut and other large seeds, and which could be quickly installed to increase or decrease the number of adjustment block to achieve hill spacing adjustment. It could Improve the quality of planting, reduce labor intensity, improve seeding efficiency.

2. The design of the adjustable inlet pipe structure and the structure of the lever, through the effective coordination with the adjustment block to effectively achieve the sowing of the adjustable, so as to effectively achieve the sowing process during the planting of the number of seed and hill spacing changes.

\section{Acknowledgements}

The study was supported by the Jiangsu Natural Science Foundation of China (BK2012518.)

Correspondence Author: LvXiaorong, College of Information \& Engineering, Sichuan Agricultural University, Ya'an, China, 1xrxj2008@163.com.

\section{References}

[1] Weimin Ding. Agricultural Mechanics [M]. Beijing: China Agriculture Press, 2011(06). In Chinese.

[2] Chinese Academy of Agricultural Mechanization Sciences. Handbook of agricultural basic design [M]. Chinese agricultural science and Technology Press, 2007(11). In Chinese.

[3] Xuanhuai Qiu. Machine design [M]. Beijing: Higher Education Press, 2014(12). In Chinese. 